\title{
Diffusion Efficiency and Bioavailability of Resveratrol Administered to Rat Brain by Different Routes: Therapeutic Implications
}

\author{
Xiao-Hong Shu $\cdot$ Li-Li Wang $\cdot$ Hong Li $•$ Xue Song • \\ Shun Shi • Jia-Yao Gu • Mo-Li Wu • Xiao-Yan Chen . \\ Qing-You Kong • Jia Liu
}

Published online: 15 January 2015

(C) The American Society for Experimental NeuroTherapeutics, Inc. 2015
Key words Resveratrol $\cdot$ blood brain barrier $\cdot$ drug administration $\cdot$ bioavailability $\cdot$ glioblastoma neurotherapeutics

\section{Introduction}

Resveratrol (trans-3,5,4'-trihydroxystilbene, $\mathrm{C}_{14} \mathrm{H}_{12} \mathrm{O}_{3}$, MW 228.2), a polyphenolic compound, possesses multifaceted pharmacological activities [1-3] and, importantly, resveratrol is not harmful to normal cells/tissues of the central nervous system [4, 5]. Because of the lipophilic nature of resveratrol, it is able to penetrate the cell membrane via simple diffusion. It is therefore thought that resveratrol can cross the blood brain barrier (BBB) to exert neuro-protective or anti-cancer activities in the brain [6].

Although in vitro cancer-suppressive effects of resveratrol have been well documented, this compound is not in common use in clinical practice largely because of its low bioavailability in target tissues/cells [7, 8]. Resveratrol is efficiently metabolized in the liver and intestine, resulting in less than $1 \%$ bioavailability of orally-administered resveratrol $[9,10]$. Furthermore, resveratrol is more favorably distributed to organs that have a rich blood supply. For example, $90 \mathrm{~min}$ after intravenous administration of $15 \mathrm{mg} / \mathrm{kg}$ resveratrol to the rats, it is present at $1.13 \pm 0.34 \mathrm{nmol} / \mathrm{g}$ in the lungs, $1.45 \pm 0.35 \mathrm{nmol} / \mathrm{g}$ in the kidneys but only $0.17 \pm 0.04 \mathrm{nmol} / \mathrm{g}$ in the brain [9]. Moreover, dose escalation and repeated resveratrol administration does not overcome this problem [11]. Consequently, it is necessary to explore alternative administration route(s) to increase brain drug concentration before resveratrol can be considered for use in the treatment of brain disorders.

Interventional therapy has been used in the treatment of human brain malignancies to reduce systemic side-effects, to avoid rapid drug metabolism and to prevent recurrence [12]. 
For instance, Carmustine (BCNU), a commonly used antiglioblastoma drug, is administered via the carotid artery approach [13] or placed directly in the resection cavity after neurosurgery [14]. Although the increased BCNU concentration can improve therapeutic outcome [13], it also has toxic effects on neurogenesis and cognitive function $[15,16]$. One of the advantages of resveratrol is its non-toxicity to normal cells, including glial cells and neurons, at effective anti-cancer doses [17]. This suggests its potential therapeutic value in the treatment of brain cancers if its ability to cross the BBB can be ascertained and its bioavailability to brain tissue can be improved. The current study aims to address the above issues using normal adult rats to explore the optimal administration approach and using rat glioblastoma cells in in vitro and in vivo therapeutic models.

\section{Materials and Methods}

\section{Routes of Resveratrol Administration}

All animal experimental protocols were approved by the Committee of Animal Care and Welfare, Dalian Medical University. All work involving experimental animals was performed in full compliance with NIH (National Institutes of Health) Guidelines for the Care and Use of Laboratory Animals. The animal experiments were performed under chloral hydrate anesthesia and all efforts were made to minimize suffering. Equal numbers of male and female Sprague-Dawley (SD) rats weighing $240 \pm 10 \mathrm{~g}$ were provided by the Experimental Animal Center of Dalian Medical University. They were housed under controlled conditions $\left(20 \pm 2{ }^{\circ} \mathrm{C}\right.$, humidity $50 \pm 20 \%$ ) with a natural light-dark cycle and allowed to adapt to the housing environment for at least one week prior to study. A stock solution of $100 \mathrm{mM}$ trans-resveratrol was diluted with physiological saline to the optimal working concentration of $500 \mu \mathrm{M}(11.4 \mu \mathrm{g} / \mathrm{ml})$ just before use.

Rats were randomized into four groups: Group 1, treated with intragastric ingestion; Group 2, treated with intraperitoneal injection; Group 3, treated with external carotid artery (ECA) injection; Group 4, treated with lumbar puncture (LP) injection. A single dose of $50 \mathrm{nmol}$ resveratrol (about $4.56 \mu \mathrm{g} /$ $100 \mathrm{~g}$ body weight) was administered to the rats through intragastric, intraperitoneal, ECA and LP routes, respectively. In each group, six rats were used at different time points. The rats were painlessly sacrificed by an animal expert of the Dalian Medical University Animal Center by cervical spinal dislocation and their brains were immediately removed at time points of 2, 5, 10, 20, 30, 60, 90 and $120 \mathrm{~min}$ after resveratrol administration. To detect systemically-administered resveratrol in the brain, 24 rats were treated with resveratrol at a dosage of $50 \mathrm{nmol}$ (about $4.56 \mu \mathrm{g} / 100 \mathrm{~g}$ body weight) by intraperitoneal injection. Six rats were then randomly selected at time points of $10,30,60$, and 90 min after drug administration. Portions of the left and right brain, cerebellum, heart, liver, spleen, lungs, kidneys, intestine and plasma were dissected on an ice bed, weighed, wrapped in aluminum foil to protect against light, snap frozen in liquid nitrogen and stored at $-80{ }^{\circ} \mathrm{C}$ until sample preparation.

\section{Cell Culture and Treatment}

Rat glioblastoma RG2 cells are sensitive to $100 \mu \mathrm{M}$ and $150 \mu \mathrm{M}$ resveratrol treatment [18]. This cell line, a kind gift from Dr. Vencossa, Department of Neurosurgery, Central Hospital of Lausanne University, Switzerland, was cultured in DMEM (Invitrogen, Grand Island, NY, USA) supplemented with $10 \%$ fetal bovine serum (Gibco Life Science, Grand Island, NY, USA) at $37^{\circ} \mathrm{C}$ in a humidified atmosphere containing $95 \%$ air and $5 \% \mathrm{CO}_{2}$ [17]. Trans-resveratrol (Sigma, St. Louis, MO, USA) was dissolved in DMSO (Sigma) to a stock concentration of $100 \mathrm{mM}$, wrapped in aluminum foil for protection against light, and stored at $-20^{\circ} \mathrm{C}$. Four groups of RG2 cells were prepared for different experimental purposes and treated with the conditions shown in Table 1. In Groups 3 and 4, novel coverslip preparation dishes, NEST-DISH (China Patent for Invention: ZL200610047607.0; NEST Biotech, Wuxi, China), were used for comprehensive sequential analyses of cancer cell drug sensitivities. Forty six cell-bearing coverslips were prepared from one NEST-DISH. The coverslips prepared were randomly separated into a normal culture group (Group N) and short-term $100 \mu \mathrm{M}, 150 \mu \mathrm{M}$ and $200 \mu \mathrm{M}$ resveratrol treatment groups (Groups R2, R3 and R4). The coverslips in the three experimental groups were exposed to resveratrol-containing media for 15, 20 or $30 \mathrm{~min}$ and then removed to dishes containing normal culture medium until the next short-term treatments. Three rounds of treatment were conducted at 24-hour intervals. After the final treatment, coverslips were harvested and fixed according to subsequent processing. The experiments were repeated three times to establish statistical confidence.

\section{Rat Intracranial Glioblastoma Model and Resveratrol Administration}

A rat intracranial glioblastoma model was established using a 68000 stereotaxic instrument (RWD Life Science, Shenzhen, China), following the method described by Valable et al. [19]. In brief, rats were anesthetized with ketamine-xylazine (90:10 mg/kg i.p.; Sigma). After shaving the scalp, a 1.5-cm incision was made along the midsagittal line to expose the skull. A burr hole was drilled through the skull with a 1-mm rotary drill to create access to the brain at the position $1 \mathrm{~mm}$ behind the bregma and $3 \mathrm{~mm}$ to the left of the midline. $1 \times 10^{6} /$ $10 \mu \mathrm{l} \mathrm{RG}-2$ cells were injected at $2 \mathrm{~mm}$ depth into the left cerebral hemisphere using a micro syringe and then the burr hole was filled with autoclaved bone wax. Fourteen days after 
Table 1 Four groups of RG2 cells for different experimental purposes and their treated manners

\begin{tabular}{|c|c|c|c|}
\hline Groups & Treatment programs & Detection methods & Detection indices \\
\hline 1 & $\begin{array}{l}\text { RG-2 cells were treated with trans-resveratrol }(50 \mu \mathrm{M}, 100 \mu \mathrm{M}, 150 \mu \mathrm{M}, 200 \mu \mathrm{M}) \text { for } \\
60 \text { min and then were collected }{ }^{\mathrm{a}}\end{array}$ & HPLC & Drug uptake \\
\hline \multirow[t]{2}{*}{2} & $\begin{array}{l}\text { Step 1: RG-2 cells were incubated with trans-resveratrol }(150 \mu \mathrm{M} \text { and } 200 \mu \mathrm{M}) \text { for } 20 \mathrm{~min} \\
\text { Step 2: RG-2 cells were re-incubated in normal medium for } 5,10,15,20,30 \text { or } 60 \mathrm{~min}\end{array}$ & \multirow[t]{2}{*}{ HPLC } & \multirow[t]{2}{*}{ Drug release } \\
\hline & Step 3: RG-2 cells and their culture medium were collected for checking drug uptake/discharge \# & & \\
\hline 3 & $\begin{array}{l}\text { Cells were daily treated with trans-resveratrol }(100 \mu \mathrm{M}, 150 \mu \mathrm{M}, 200 \mu \mathrm{M}) \text { for } 15,20 \text { or } 30 \mathrm{~min} \\
\text { and last for } 3 \text { days }\end{array}$ & MTT & Cell viability \\
\hline 4 & $\begin{array}{l}\text { Step 1: RG-2 cells were daily treated with trans-resveratrol }(100 \mu \mathrm{M}, 150 \mu \mathrm{M} \text { or } 200 \mu \mathrm{M}) \text { for } 20 \\
\text { min and lasted for } 3 \text { days }\end{array}$ & IF & Autophagic activity \\
\hline & $\begin{array}{l}\text { Step 2: Cell-bearing coverslips were fixed in cold acetone for LC-3 and Beclin-1 } \\
\text { immunofluorescent/IF examinations }\end{array}$ & & \\
\hline
\end{tabular}

a $400 \mu 1$ lysates of $5 \times 10^{6}$ cells were prepared for HPLC analysis

RG2 cell implantation, the formation of intracranial tumors was ascertained by nuclear magnetic resonance imaging/NMRI [20]. Fifteen tumor-bearing rats were treated with $2.74 \mu \mathrm{g} / 100 \mathrm{~g}$ body weight resveratrol via the LP route and then scarified at 2, 5, 10, 20 and 30 minute time points (3 rats/time point) for high performance liquid chromatography/HPLC determination of resveratrol concentrations in glioblastomas and their surrounding brain tissues. The remaining tumor-bearing rats were divided into groups (three rats per group). One group had no treatment, and the other two groups were administered $50 \mu \mathrm{l} \quad 0.02 \%$ DMSO-containing normal saline solution or $50 \mu \mathrm{l} 500 \mu \mathrm{M}$ resveratrol via LP three times at 3 day intervals [21]. The animals were painlessly scarified and their brains were removed within 2 min and treated according to subsequent experiments.

\section{Sample Preparation}

The appropriate amount of each tissue sample was prepared from the frozen rat brains, intracranial transplanted tumors or other organs. The amount of tissue used was calculated by measuring tissue weight differences before and after sampling. The sample tissues were extracted with $416 \mu \mathrm{l}$ methanol and $84 \mu \mathrm{l}$ IS (1,8-dihydroxyanthraquinone, $200 \mu \mathrm{g} / \mathrm{ml})$ in a centrifuge tube. The tissue homogenates were vortex-mixed for $5 \mathrm{~min}$ and centrifuged at $\mathrm{rcf} 10,000 \mathrm{x}$ g for $10 \mathrm{~min}$ at $4{ }^{\circ} \mathrm{C}$. The supernatant was transferred to a second tube. The residue was extracted two more times with $1 \mathrm{ml}$ methanol by vigorous vortex agitation for $5 \mathrm{~min}$, followed by centrifugation at rcf $10,000 \times \mathrm{g}$ for $10 \mathrm{~min}$ at $4{ }^{\circ} \mathrm{C}$. The organic solvent of the combined supernatants was evaporated to a final volume of $400 \mu \mathrm{l}$, and subsequently placed in a sealed amber vial for HPLC analysis. In the case of resveratrol-treated RG2 cells, they were scraped off, washed three times with PBS (pH 7.4), and lysed with $416 \mu \mathrm{l}$ PBS and $84 \mu \mathrm{l}$ IS by sonication. Cells cultured for 60 min in medium with the same working concentration of DMSO $(0.2 \%)$ were used as a background control. The collected culture medium and cell lysates were centrifuged at $12,000 \mathrm{rpm} / \mathrm{min}$ for $10 \mathrm{~min}$ at $4{ }^{\circ} \mathrm{C}$, and this was followed by supernatant purification with Cleanert PEP-SPE cartridges (60 mg; Agela Technol, Wilmington, PA, USA) [17]. The eluates were evaporated to a final volume of $400 \mu \mathrm{l}$, and subsequently placed in a sealed amber vial for HPLC analysis.

\section{Sample Analysis}

The prepared samples were analyzed by HPLC-Diode array detector/DAD. Chromatographic separation of the samples was performed on a LaChrom C18 column ( $5 \mu \mathrm{m}, 4.6 \mathrm{~mm} \times$ 250 mm; HITACHI, Japan). The HPLC system (HITACHI Chromaster 5000, Japan) consisted of a HITACHI Chromaster 5430 DAD, 5310 column oven, 5210 auto sampler and 5110 pump. Quantization of resveratrol was performed by a method that had previously been validated in terms of intra-day and inter-day precision, accuracy and recovery. The mobile phase consisted of two phases, phase A was $20 \%$ acetonitrile and phase B was $80 \%$ acetonitrile (acetic acid adjusted $\mathrm{pH} 3.5$ ). Resveratrol was separated with gradient elution starting with 0-14 min, linear gradient from $100 \%$ to $60 \% \mathrm{~A} ; 14-20 \mathrm{~min}$, linear from $60 \%$ to $0 \% \mathrm{~A} ; 20$ min with $0 \%$ solvent $\mathrm{A}$ to $30 \mathrm{~min}$, followed by washing and reconditioning the column. The eluate was monitored using a DAD at $303 \mathrm{~nm}$, the temperature of the column was kept at $30^{\circ} \mathrm{C}$, the flow rate was $1 \mathrm{ml} / \mathrm{min}$ and injection volume was $10 \mu \mathrm{l}$. The mean extraction recovery of resveratrol from brain tissue was $96.1 \pm 4.6 \%$ (mean \pm relative standard deviation/RSD, $n=5$ ). The RSD of intra-day and inter-day assay variations were all less than $10 \%$ and were within acceptable limits to meet the guidelines for bioanalytical method validation which is considered to be lower than $20 \%$ [9]. The accuracy of the method was also acceptable, with the deviation between the nominal 
concentration and the calculated concentration for resveratrol well below the $15 \%$ limit [9]. Resveratrol was stable under the storage and assay conditions.

Evaluation of Uridine 5'-diphospho-glucuronosyltransferase (UGT) Expression

Resveratrol can be biotransformed into resveratrol glucuronide [18] and the UGT genes, UGT1A6 and UGT2B7 and UDP glycosyltransferase 8 (UGT8) are preferentially expressed in rat brain $[22,23]$. Using a previously described method [18], western blot analysis was performed on sample proteins prepared from each experimental group using rabbit anti-UGT1A6, anti-UGT2B7 and anti-UGT8 antibodies (Protein Tech Group, Inc., Chicago, USA) at dilution rates of $1: 600,1: 600$, and $1: 500$, respectively. The results were compared with those obtained from normal rat brain tissues. In parallel, tissue microarrays were constructed with the tissue spots of the corresponding brain regions and their sections were subjected to immunohistochemical staining using the same antibodies against UGT1A6, UGT2B7 and UGT8 at dilution rates of $1: 80,1: 100$, and $1: 100$, respectively. Sections without first antibody incubation were processed as background controls. According to the labeling intensity, the staining results were evaluated by two independent researchers and scored as negative (-) if no immune labeling was observed in target tissues, weakly positive $(+)$ if the labeling was faint, and moderately to strongly positive $(++$ or +++$)$ when the labeling was stronger or distinctly stronger than (+).

\section{Immunofluorescence Detection of Autophagy-related} Proteins

Double-labeling immunofluorescence was performed on RG2 cells and rat brain tissues obtained from each of the experimental groups. The cells or the brain tissues were rinsed with PBS, then fixed for $20 \mathrm{~min}$ in cold acetone and stored at $-20{ }^{\circ} \mathrm{C}$. After being blocked with $10 \%$ goat serum in PBS for $20 \mathrm{~min}$, the cells or the brain tissues were incubated overnight at $4{ }^{\circ} \mathrm{C}$ with rabbit anti-LC-3 (1:50) and rat anti-Beclin-1 (1:100) antibodies in a humidified chamber, followed by coincubation with FITC-conjugated goat anti-rabbit IgG (1:100; Santa Cruz, CA, USA) and TRITC-conjugated rabbit anti rat $\operatorname{IgG}(1: 100$; Santa Cruz, CA, USA) in a $37{ }^{\circ} \mathrm{C}$ humidified chamber for $60 \mathrm{~min}$ in darkness. Nuclei were labeled with DAPI [4',6-diamidino- 2phenylindole,2-(4-amidinophenyl)-1H-indole-6carboxamidine]. After being sealed with fluorescence mounting medium, the cells and the rat brain tissues were observed and photographed under a fluorescence microscope (BX53F, Olympus, Japan). Meanwhile, the effects of LP-administered resveratrol on rat intracranial glioblastomas formed by RG2 cells were evaluated by $\mathrm{H} / \mathrm{E}$ morphological staining and the TdT mediated dUTP nick end labeling (TUNEL) apoptosis assay (Promega Corporation, Madison, WI, USA) according to methods described elsewhere [18].

\section{Statistical Analysis}

Statistical analyses were performed using Statistical Product and Service Solutions (SPSS) 13.0. Data are given as the means \pm SD. Statistical analyses were performed using oneway ANOVA and $p$ values $<0.05$ were considered to indicate significance.

\section{Results}

Quantitative Analysis of Resveratrol in the Brain

Resveratrol extracted from rat brain tissue samples was identified and quantified by HPLC/DAD chromatography [9]. The chromatograms of resveratrol in normal rat brain tissue, normal rat brain tissue spiked with $2.5 \mu \mathrm{M}$ resveratrol and IS, and brain tissue obtained from rats $10 \mathrm{~min}$ after injection with $50 \mathrm{nmol}$ resveratrol by ECA or LP are shown in Fig. 1. The retention times of resveratrol and the internal standard were
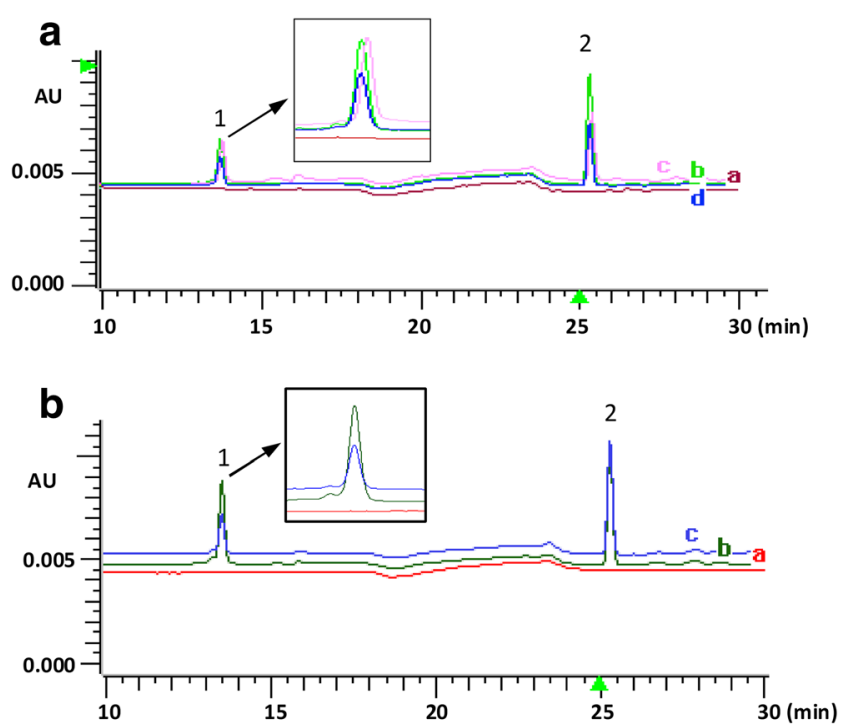

Fig. 1 Representative HPLC/DAD analysis of resveratrol in rat brain tissue samples and RG2 glioblastoma cells. (a) HPLC/DAD chromatograms of normal rat brain tissue $(a)$, normal rat brain tissue spiked with $2.5 \mu \mathrm{M}$ resveratrol and IS (b), brain tissue obtained from the rat $10 \mathrm{~min}$ after $20 \mathrm{nmol}$ resveratrol injection through ECA $(c)$ and LP $(d)$. (b) HPLC/DAD chromatogram of control cell lysates (a), control cell lysates spiked with $3.5 \mu \mathrm{M}$ resveratrol and internal standard/IS (b), and cells treated daily with $150 \mu \mathrm{M}$ resveratrol for $60 \min$ for 3 days $(c)$. Peaks: 1. trans-resveratrol; 2. 1,8-dihydroxy anthraquinone (IS) 
Table 2 Resveratrol levels in rat major organs at different time points $(n=6)$ after intraperitoneal administration

Resveratrol availability (nmol/g)

Time (min) Heart Liver $\quad$ Spleen Lungs Kidneys $\quad$ Intestine $\quad$ Plasma $(\mu \mathrm{M})$ Brain

Left brain Right brain Cerebellum

\begin{tabular}{|c|c|c|c|c|c|c|c|c|c|c|}
\hline 10 & n.d. & n.d. & n.d. & n.d. & n.d. & n.d. & $0.214 \pm 0.106^{\mathrm{a}}$ & n.d. & n.d. & n.d. \\
\hline 30 & n.d. & n.d. & n.d. & n.d. & n.d. & $1.894 \pm 1.226^{\mathrm{a}}$ & $0.426 \pm 0.271^{\mathrm{a}}$ & n.d. & n.d. & n.d. \\
\hline 60 & n.d. & $0.023 \pm 0.001^{\mathrm{a}}$ & n.d. & $0.066 \pm 0.047^{\mathrm{a}}$ & $0.144 \pm 0.899^{\mathrm{a}}$ & $2.241 \pm 1.943^{\mathrm{a}}$ & $0.293 \pm 0.134^{\mathrm{a}}$ & n.d. & n.d. & n.d. \\
\hline 90 & n.d. & n.d. & n.d. & n.d. & n.d. & $0.383 \pm 0.176^{\mathrm{a}}$ & n.d. & n.d. & n.d. & n.d. \\
\hline
\end{tabular}

n.d. not detectable

${ }^{\text {a }}$ Compared with the brain, $P<0.01$

$13.5 \mathrm{~min}$ and $25.3 \mathrm{~min}$, respectively. No additional peak was observed at or near the retention time of resveratrol,

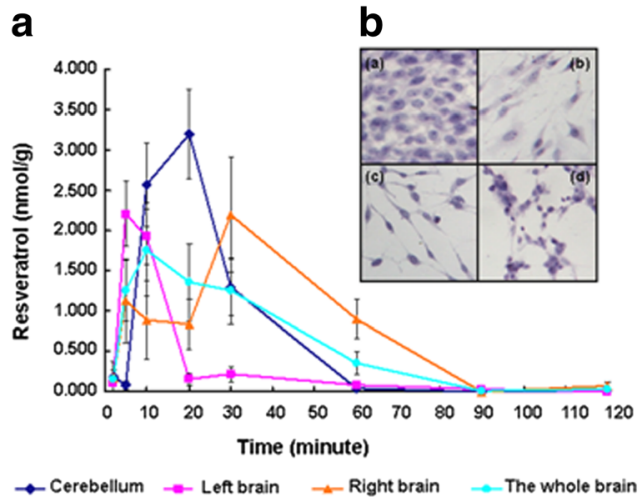
$\begin{array}{llll}\text { (a) Normal } & \text { (b) } 100 \mu M \text { Res } 30 \mathrm{~min} & \text { (c) } 150 \mu \mathrm{M} \text { Res } 30 \mathrm{~min} & \text { (d) } 200 \mu \mathrm{M} \text { Res } 30 \mathrm{~min}\end{array}$

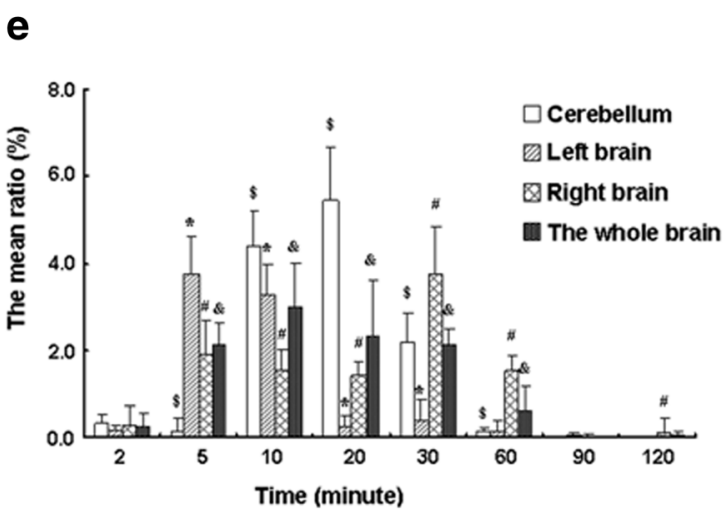

Fig. 2 Quantification of ECA and LP-administered resveratrol in rat brains. (a) Trans-resveratrol concentrations in the cerebellum, left brain, right brain and whole brain 2, 5, 10, 20, 30, 60, 90 and 120 min after $100 \mu \mathrm{l} 500 \mu \mathrm{M}$ resveratrol ECA injection. (b) H\&E staining performed on RG2 cells treated with $100 \mu \mathrm{M}, 150 \mu \mathrm{M}$ or $200 \mu \mathrm{M}$ resveratrol for $30 \mathrm{~min}$ and then cultured normally for 3 days. (c) Trans-resveratrol concentrations in the cerebellum, left brain, right brain and whole brain 2, 5, 10, 20, 30 and $60 \mathrm{~min}$ after LP injection of $50 \mathrm{nmol}$ resveratrol. (d) H\&E staining performed on RG2 cells treated for 20 min with $100 \mu \mathrm{M}$, $150 \mu \mathrm{M}$ or $200 \mu \mathrm{M}$ resveratrol and then cultured normally for 3 days. Values are means $\pm \mathrm{SD}, n=6$. (e) Highly variable and time-dependent mean drug uptake ratios of ECA-administered resveratrol $(4.56 \mu \mathrm{g} /$ $100 \mathrm{~g}$ body weight) in brains. \$, the mean drug uptake ratio of the suggesting that the extraction procedure was reliable in obtaining highly purified samples for HPLC analysis.

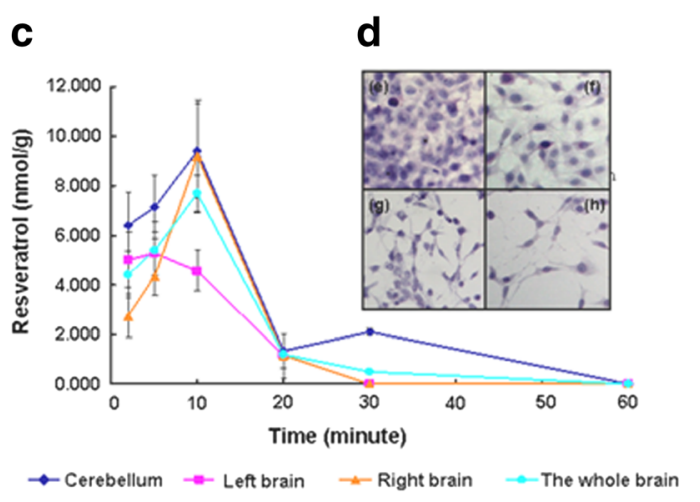

$\begin{array}{llll}\text { (e) Normal (f) } 100 \mu \mathrm{M} \text { Res } 20 \mathrm{~min} & \text { (g) } 150 \mu \mathrm{M} \text { Res } 20 \mathrm{~min} & \text { (h) } 200 \mu \mathrm{M} \text { Res } 20 \mathrm{~min}\end{array}$

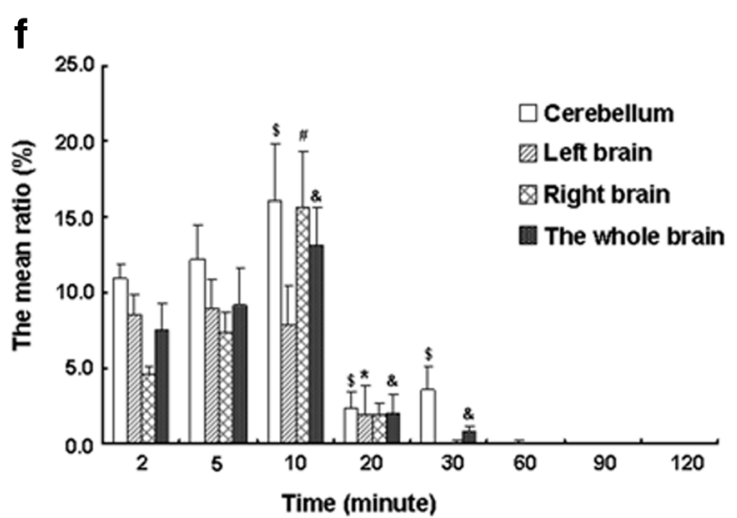

cerebellum 2 min after ECA administration, $P<0.05$; *, the mean drug uptake ratio of the left brain 2 min after ECA administration, $P<0.05$; \#, the mean drug uptake ratio of the right brain 2 min after ECA administration, $P<0.05 ; \&$, the mean drug uptake ratio of the whole brain 2 min after ECA administration, $P<0.05$. (f) The mean drug uptake ratios of $4.56 \mu \mathrm{g} / 100 \mathrm{~g}$ body weight resveratrol administered by LP in brains were highly variable in a time-dependent manner. $\$$, the mean drug uptake ratio of the cerebellum 2 min after LP administration, $P<0.05 ; *$, the mean drug uptake ratio of the left brain 2 min after LP administration, $P<0.05$; \#, the mean drug uptake ratio of the right brain 2 min after LP administration, $P<0.05$; \&, the mean drug uptake ratio of the whole brain 2 min after LP administration, $P<0.05$ 
Variability of Systemically-administered Resveratrol in Rat Organs

Using the HPLC protocol, resveratrol in rat brain tissues and other major organs (heart, liver, spleen, lungs, kidneys, intestine and plasma) was measured at time points of 10, 30, 60 and $90 \mathrm{~min}$ after $4.56 \mu \mathrm{g} / 100 \mathrm{~g}$ (resveratrol/body weight) intraperitoneal (i.p.) injection. The concentrations of resveratrol detected were highly variable in time-dependent and organ-related fashions (Table 2). Resveratrol was detected in the extracts of liver $(0.023$ $\pm 0.001 \mathrm{nmol} / \mathrm{g})$, lungs $(0.066 \pm 0.047 \mathrm{nmol} / \mathrm{g})$, kidneys $(0.144 \pm 0.899 \mathrm{nmol} / \mathrm{g})$, intestine $(2.241 \pm 1.943 \mathrm{nmol} / \mathrm{g})$ and plasma $(0.293 \pm 0.134 \mu \mathrm{M})$ but not in the spleen and brains $60 \mathrm{~min}$ after administration [24]. When $4.56 \mu \mathrm{g} / 100 \mathrm{~g}$ body weight of resveratrol was administered intragastrically, resveratrol was only detected at different time points $(2,5,10,20,30,60,90$ and $120 \mathrm{~min})$ in the intestinal extracts (data not shown).

Increased Availability of ECA- and LP-administered Resveratrol in Rat Brains

Trans-resveratrol was administered to rats by ECA and LP and brain concentrations were measured at different time points $(2,5,10,20,30,60,90$ and $120 \mathrm{~min})$ after administration. In the case of right ECA injection, resveratrol appeared in the left and right cerebrum as well as in the cerebellum within $2 \mathrm{~min}$ after administration (Fig. 2a). Its highest levels were $3.195 \pm 0.550 \mathrm{nmol} / \mathrm{g}$ after $20 \mathrm{~min}$ in the cerebellum, $2.206 \pm 0.402 \mathrm{nmol} / \mathrm{g}$ after $5 \mathrm{~min}$ in the left cerebrum and $2.198 \pm 0.711 \mathrm{nmol} / \mathrm{g}$ after $30 \mathrm{~min}$ in the right cerebrum. The peak resveratrol concentration in the whole brain appeared after $10 \mathrm{~min}$ $(1.759 \pm 0.577 \mathrm{nmol} / \mathrm{g})$ and the dwell time was approximately $120 \mathrm{~min}$. When the brain samples of the LP group were analyzed, trans-resveratrol was detected in the cerebellum and the left and right cerebra within 2 min after injection, and its peak concentrations reached $5.277 \pm 0.863 \mathrm{nmol} / \mathrm{g}$ after $10 \mathrm{~min}$ in the left cerebrum and $9.419 \pm 1.898 \mathrm{nmol} / \mathrm{g}$ and $9.200 \pm 2.266 \mathrm{nmol} / \mathrm{g}$ in the cerebellum and right cerebrum, respectively (Fig. 2c). The dwell time and the peak concentration of resveratrol in the whole brain were about $60 \mathrm{~min}$ and $7.70 \pm 0.734 \mathrm{nmol} / \mathrm{g}$ after $10 \mathrm{~min}$, respectively. Only trans-resveratrol was detected in brain samples (Fig. 1a). When the same dose of resveratrol was administered by ECA and LP routes, the mean ratios of resveratrol at different time points $(2,5,10,20,30,60,90$ and $120 \mathrm{~min}$ ) in the cerebellum, left brain, right brain and whole brain between the two routes were highly variable in a time-dependent fashion (Fig. 2e and f).
Short-term Resveratrol Treatment Suppressed RG2 Cell Growth

RG2 cells were treated daily with $100 \mu \mathrm{M}, 150 \mu \mathrm{M}$ or $200 \mu \mathrm{M}$ resveratrol for 15,20 or $30 \mathrm{~min}$ for 3 days. MTT assays revealed that the growth of RG2 cells was suppressed in time- and dose-dependent manners, accompanied with morphological alterations and cell death (Fig. 3a). Autophagic activity is known as an indicator of the early cellular response to drug treatment [25]. Immunofluorescence staining showed
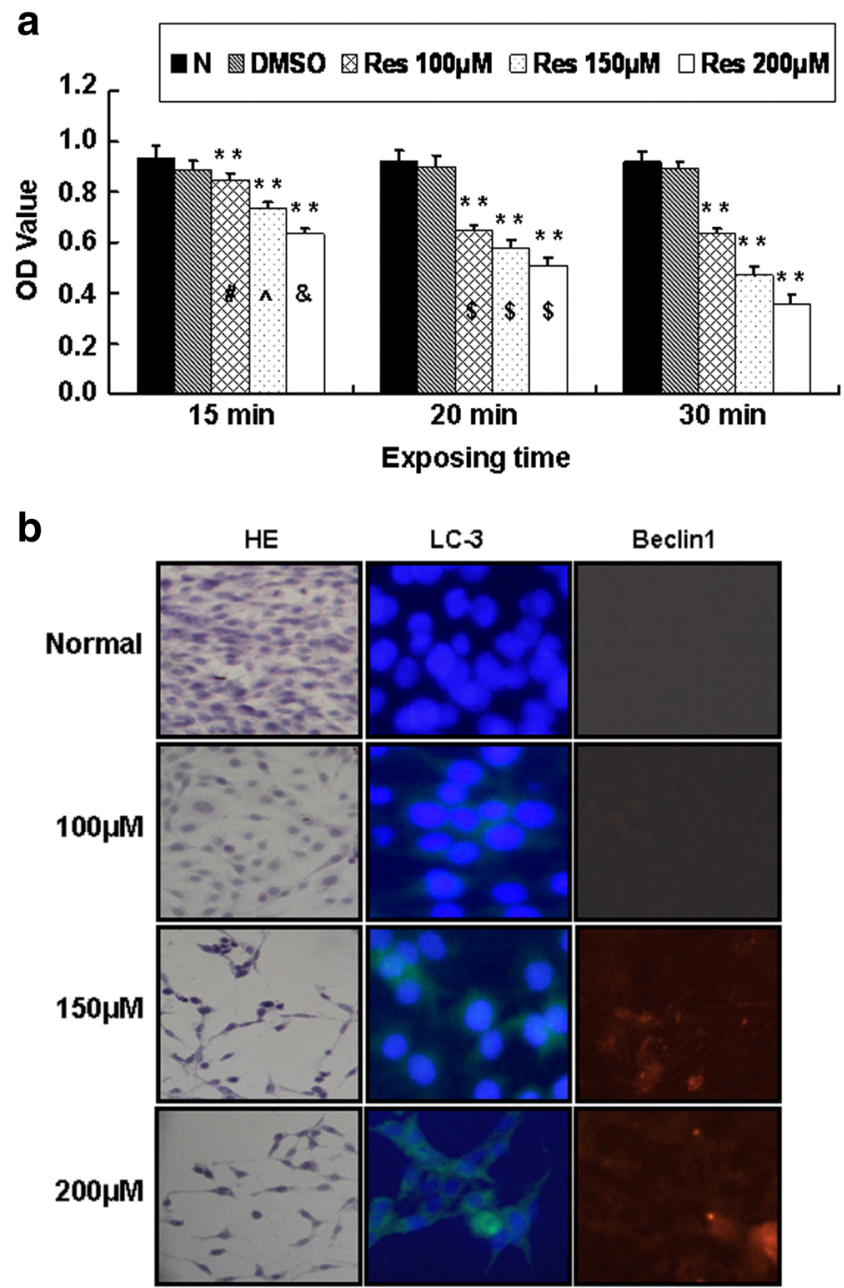

Fig. 3 Morphological and autophagic evaluation of RG2 cells after short-term resveratrol treatment. (a) MTT assays performed at the 96hour treatment point showed that short-term resveratrol exposure suppressed RG2 cell growth in time- and dosage-related fashions. **, compared with $\mathrm{N}$ group, $P<0.05$; \#, compared among 15-min, 20-min or 30-min $100 \mu \mathrm{M}$ resveratrol-treated groups, $P<0.01$; $\wedge$, compared among 15-min, 20-min or 30-min $150 \mu \mathrm{M}$ resveratrol-treated groups, $P<0.01$; \&, compared among 15 -min, 20-min or 30-min $200 \mu \mathrm{M}$ resveratrol-treated groups, $P<0.01 ; \$$, compared among $100 \mu \mathrm{M}$, $150 \mu \mathrm{M}$ and $200 \mu \mathrm{M}$ resveratrol-treated groups at $20 \mathrm{~min}$ and $30 \mathrm{~min}$, $P<0.01$. Data points are expressed as means \pm SD from three determinations. (b) H\&E staining and immunofluorescence detection of LC-3 (green) and Beclin-1 (red) expression in RG2 cells treated daily with $100 \mu \mathrm{M}, 150 \mu \mathrm{M}$ or $200 \mu \mathrm{M}$ resveratrol for $20 \mathrm{~min}$ and for 3 days. Normally cultured RG2 cells are cited as background control 
that the autophagy-related proteins, LC3 and Beclin-1, were undetectable in normally cultured RG2 cells and became distinctly enhanced in cells after daily 20 minute treatments with $150 \mu \mathrm{M}$ and, especially, $200 \mu \mathrm{M}$ resveratrol for 3 days (Fig. 3b).

\section{Evaluation of Resveratrol Availability in RG2 Cells}

Resveratrol uptake by RG2 cells was evaluated after 60 minute treatments with $50 \mu \mathrm{M}, 100 \mu \mathrm{M}, 150 \mu \mathrm{M}$ and $200 \mu \mathrm{M}$, followed by three washes with PBS (Fig. 4a). Resveratrol concentrations in $400 \mu 1$ lysates of $5 \times 10^{6} \mathrm{RG} 2$ cells were determined as undetectable in $50 \mu \mathrm{M}, 1.747 \pm 0.709 \mu \mathrm{M}$ in $100 \mu \mathrm{M}, 30.433 \pm 2.691 \mu \mathrm{M}$ in $150 \mu \mathrm{M}$ and $113.161 \pm$ $5.589 \mu \mathrm{M}$ in $200 \mu \mathrm{M}$ treated cells. Only trans-resveratrol was detected in the cell lysates (Fig. 1b). It was found that cellular resveratrol uptake by $150 \mu \mathrm{M}$ resveratrol-treated RG2 cells was almost two times higher than the whole brain peak concentration of resveratrol administered by ECA $(1.759 \pm$ $0.577 \mathrm{nmol} / \mathrm{g} ;(15.000 \pm 4.920 \mu \mathrm{M})$ but only $46.8 \%$ of the peak concentration of resveratrol administered by LP (7.700 $\pm 0.734 \mathrm{nmol} / \mathrm{g} ; 65.662 \pm 6.259 \mu \mathrm{M})$.

Comparison of Sequential Drug Uptake and Release Rates of RG2 Cells

Cellular uptake and release of resveratrol in RG2 cells at the different post-treatment time points $(5,10,15,20,30$ and $60 \mathrm{~min}$ ) were evaluated by HPLC after treatment for $20 \mathrm{~min}$ with $150 \mu \mathrm{M}$ or $200 \mu \mathrm{M}$ resveratrol. The results revealed that concentrations of resveratrol in the cell culture medium gradually increased to a maximum after $60 \mathrm{~min}(16.608 \pm 1.562$ for
Fig. 4 Evaluation of resveratrol availability and comparison of sequential drug uptake and release rates of RG2 cells. (a) The uptake of resveratrol in RG2 cells and (b) the mean ratios of extracellular and intracellular drug concentrations after treating RG2 cells with $50 \mu \mathrm{M}, 100 \mu \mathrm{M}$, $150 \mu \mathrm{M}$ and $200 \mu \mathrm{M}$ resveratrol for $60 \mathrm{~min}$. **, $P<0.01 \mathrm{vs}$. the cells treated with $200 \mu \mathrm{M}$ resveratrol. (c) Drug release and (d) drug uptake after 20-min $150 \mu \mathrm{M}$ resveratrol treatment of RG2 cells at different posttreatment time points. $* * P<0.05$ vs. the cell culture medium discharge after 5 min. \#, $P<0.05$ vs. the cell discharge after 5 min. (e) Drug release and (f) drug uptake after 20-min $200 \mu \mathrm{M}$ resveratrol treatment of RG2 cells at different post-treatment time points. $\&, P<0.05$ vs. the cell culture medium discharge after 5 min. $\$, P<0.05$ vs. the cell discharge after $5 \mathrm{~min}$. Data points were expressed as means \pm SD from three determinations a

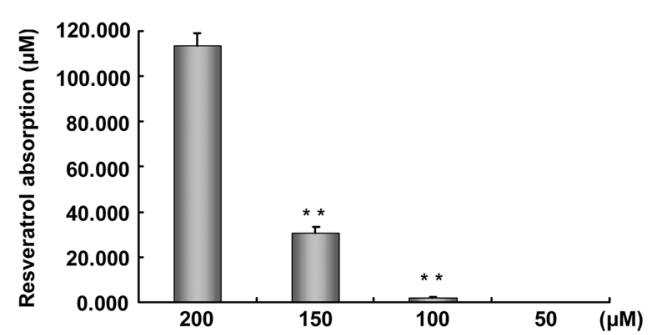

C

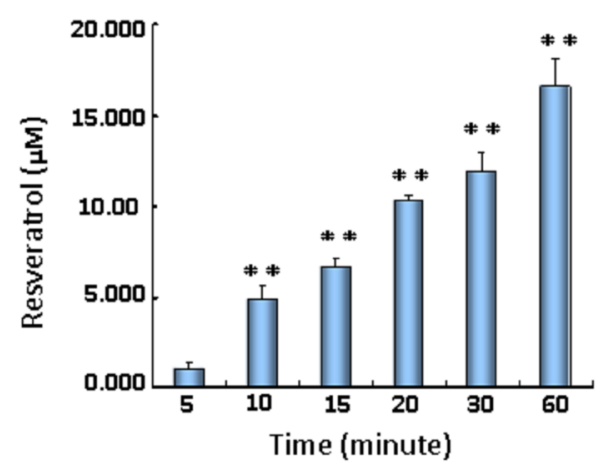

e

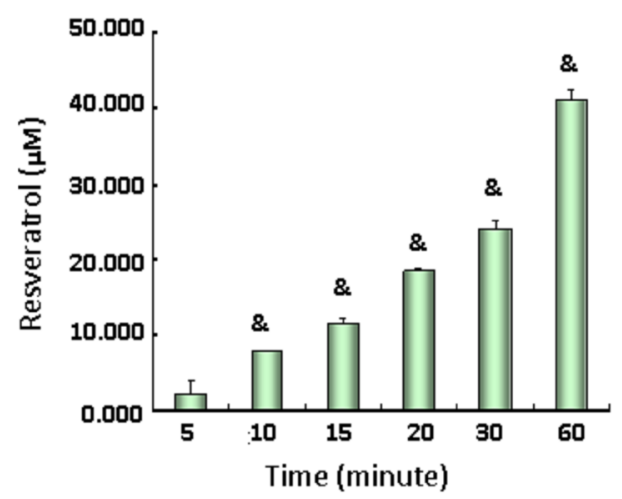

b
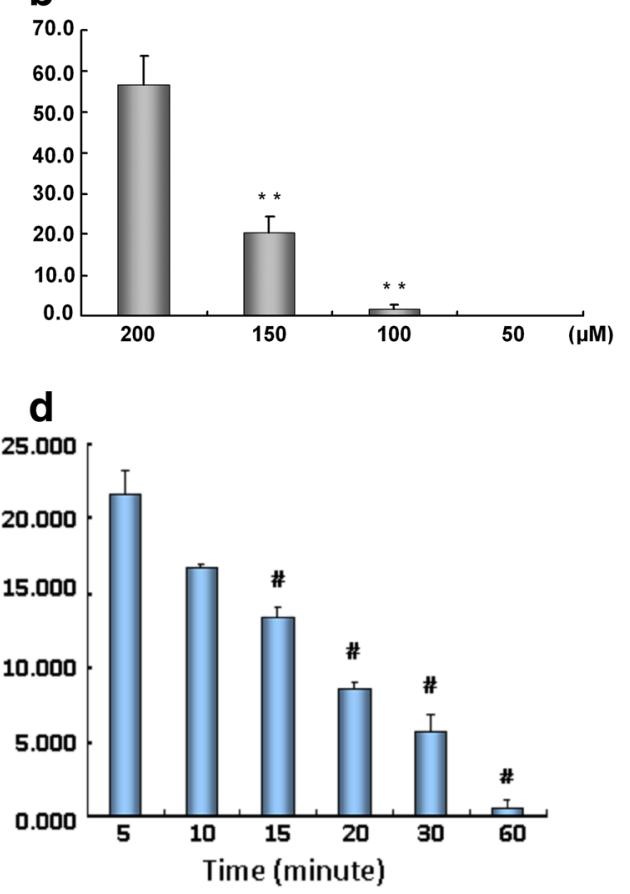

f

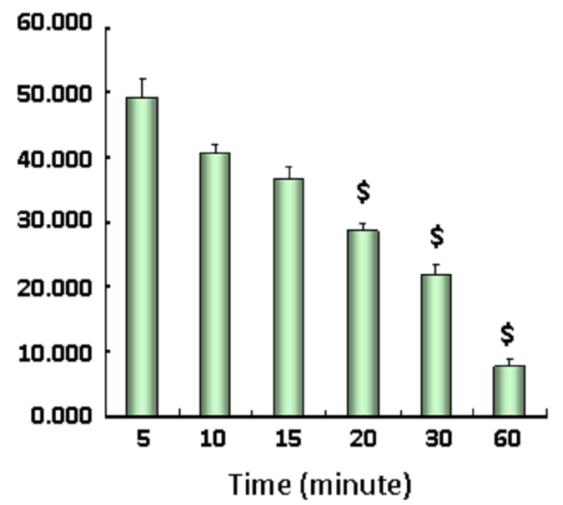


$150 \mu \mathrm{M}, 40.984 \pm 1.437$ for $200 \mu \mathrm{M})$; the drug concentration in cells increased to a maximum after $5 \min (21.584 \pm 1.494$ in $150 \mu \mathrm{M}, 49.344 \pm 2.761$ in $200 \mu \mathrm{M})$ and then decreased with post-treatment time. Resveratrol release from short-term $150 \mu \mathrm{M}$ and $200 \mu \mathrm{M}$ resveratrol-treated RG2 cells was different in time- and dose-dependent fashions (Fig. 4c-f). The mean ratios of extracellular to intracellular drug concentrations of $50 \mu \mathrm{M}, 100 \mu \mathrm{M}, 150 \mu \mathrm{M}$ and $200 \mu \mathrm{M}$ resveratroltreated RG2 cells were $0.0 \%, 1.7 \%, 20.3 \%$ and $56.6 \%$, respectively (Fig. 4b).

Unchanged UGT Expression Levels in Resveratrol-treated Brains

To investigate the involvement of UGT1A6, UGT2B7 and UGT8 in resveratrol glucuronidation, their expression in rat brains with and without resveratrol treatment was examined. The results showed that the levels of UGTs were almost unchanged in rat brains $60 \mathrm{~min}$ after resveratrol administration via any route used (Fig. 5a). Accordingly, tissue microarraybased immunohistochemical staining revealed no distinct change in UGT1A6, UGT2B7, or UGT8 levels between normal brains and brains treated for 60 min with resveratrol administered by any route (Fig. 5b). The expression levels of UGTs were classified as negative (-), weakly positive $(+)$, and moderately to strongly positive ( ++ to +++$)$ and their frequencies are summarized in Fig. 5c.

\section{Inhibitory Effects of LP-administered Resveratrol} on Intracranial glioblastomas

The amounts of resveratrol in $0.08 \mathrm{~g}$ of rat intracranial glioblastomas and tumor-surrounding tissues were counted at 2, 5, 10, 20 and $30 \mathrm{~min}$ after LP administration of trans-resveratrol. As shown in Fig. 6a, the average resveratrol concentration in tumor tissues steadily increased from $1.822 \pm 0.378 \mathrm{nmol} / \mathrm{g}$ $(15.487 \pm 3.220 \mu \mathrm{M})$ at $2 \mathrm{~min}$ to $5.427 \pm 0.426 \mathrm{nmol} / \mathrm{g}$ $(46.238 \pm 3.629 \mu \mathrm{M})$ at $10 \mathrm{~min}$, then dropped to $1.392 \pm$ $0.281 \mathrm{nmol} / \mathrm{g}(11.861 \pm 2.394 \mu \mathrm{M})$ at $20 \mathrm{~min}$ and finally reached $0.229 \pm 0.162 \mathrm{nmol} / \mathrm{g}(1.951 \pm 1.380 \mu \mathrm{M})$ at $30 \mathrm{~min}$. The resveratrol uptake in brain tissues surrounding tumors followed a similar pattern to that of tumor tissues but at relatively lower levels; for instance, resveratrol concentration was $1.719 \pm 0.010 \mathrm{nmol} / \mathrm{g}(14.646 \pm 0.085 \mu \mathrm{M})$ at $2 \mathrm{~min}, 4.687 \pm$ $0.514 \mathrm{nmol} / \mathrm{g}(39.933 \pm 04.378 \mu \mathrm{M})$ at $10 \mathrm{~min}$ and $0.257 \pm$ $0.207 \mathrm{nmol} / \mathrm{g}(2.190 \pm 1.763 \mu \mathrm{M})$ at $30 \mathrm{~min}$. In accordance with in vitro findings, the expression of LC-3 and Beclin-1 was up-regulated and remarkable apoptotic cell death appeared in glioblastoma tissues after three days of daily $50 \mu \mathrm{l}$ $500 \mu \mathrm{M}$ resveratrol LP administration (Fig. 6b), while no such alteration was observed in the tumor-surrounding regions (data not shown). Additionally, more extensive cell death occurred in regions that have a rich blood supply.
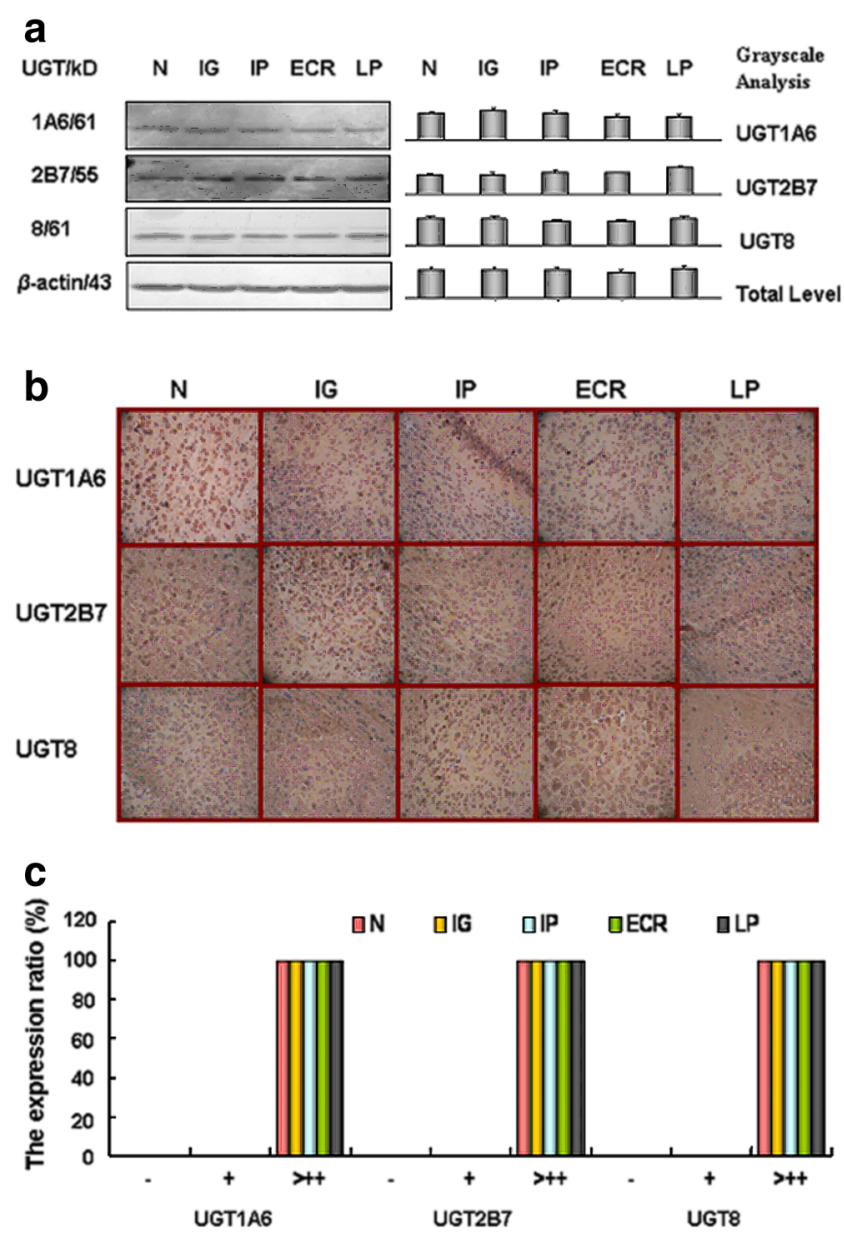

Fig. 5 Unchanged UGT expression levels in resveratrol-treated brains. (a) Western blot analyses revealed no effect of resveratrol on UGT1A6, UGT2B7, or UGT8 expression in rat brain tissues $60 \mathrm{~min}$ after drug administration via four routes. Bars represent means \pm SD from three independent experiments. ${ }^{*}, P<0.05$ in comparison with rat normal brain tissues. (b) Immunohistochemical demonstration of UGT1A6, UGT2B7, and UGT8 expression patterns in normal rat brain tissues and in rat brains treated by resveratrol for $60 \mathrm{~min}$ through the four administration routes. (c) Tissue microarray-based immunohistochemical profiling of brain associated UGT1A6, UGT2B7, and UGT8 ratios in rat brains without and with 60 -min resveratrol treatment. (-), Negative immunolabeling of target brain tissues; $(+)$, weakly positive immunolabeling; $(++)$, stronger immunolabeling. $(\mathrm{N})$, untreated brain tissues; (IG), intragastric injection; (IP), intraperitoneal injection; (ECA), external carotid artery injection; (LP), lumbar puncture injection

\section{Discussion}

Trans-resveratrol, a non-toxic natural product, is known as a lipid-soluble peroxyl radical scavenger with potent antioxidative activities [26]. In animal models, it is neuroprotective after traumatic brain injury and also protects against diabetic oxidative damage by ameliorating oxidative-stress markers in the brain [27,28]. Meanwhile, this compound possesses cancer suppression activity on a variety of human and rodent cancers [29-31] including the primary brain malignancies $[18,22,32]$. Moreover, the effective anti-cancer dose of 


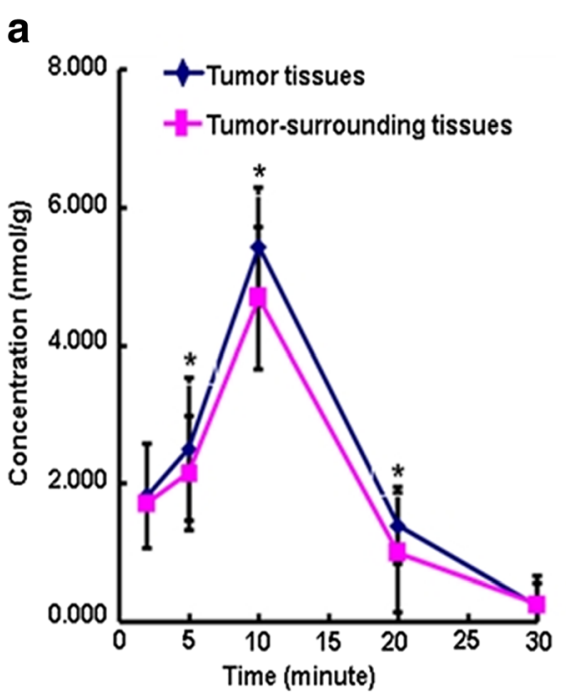

Fig. 6 Bioavailability and biological effects of lumbar punctureadministered resveratrol in a rat RG2-formed intracranial glioblastoma model. (a) trans-resveratrol concentrations in $0.08 \mathrm{~g}$ of glioblastoma and tumor-surrounding tissues at different time points, 2, 5, 10, 20 and $30 \mathrm{~min}$, after LP-administration of resveratrol $(2.74 \mu \mathrm{g} / 100 \mathrm{~g}$ body weight). Values are represented as means $\pm \mathrm{SD}, n=6 .{ }^{*}$, concentrations

resveratrol exerts few harmful effects on primary cultures of rat glial cells and neurons [18]. These data strongly suggest therapeutic potential of resveratrol in the treatment of brain injuries and malignancies. However, this remains unclear because the diffusion efficiency of resveratrol through the BBB and bioavailability in the brain of systemically-administered resveratrol are not well understood. The above issues are addressed in the present study by measuring brain drug concentrations after injecting rats with resveratrol via intragastric, intraperitoneal, LP, external artery and intracranial routes and then comparing them with the amounts of resveratrol in rat RG2 glioblastoma cells treated for a short time by effective doses of the drug.

The first step of the present study was to investigate the distribution and concentrations of systemically-administered resveratrol in the major rat organs at the time points of 2, 5, 10, $30,60,90$ and $120 \mathrm{~min}$ after administration. It was found that resveratrol was only detected in the intestine when the dose of $4.56 \mu \mathrm{g} / 100 \mathrm{~g}$ body weight was employed and became detectable in the brain when a dose of $68.4 \mu \mathrm{g} / 100 \mathrm{~g}$ body weight was administered (data not shown). These results suggest that although resveratrol is able to cross the BBB, it does not reach therapeutic levels in the brain by conventional systemic administration routes. It is therefore necessary to explore alternative approaches to increase brain resveratrol bioavailability to achieve neuroprotection and tumor inhibition.

Currently, ways of delivering drugs to the brain include carotid artery injection [33] and LP injection [34]. Intracarotid administration can increase the concentrations of anti-cancer agents in brain tumors with decreased systemic toxicity [33]. For example, tumor-bearing rats were

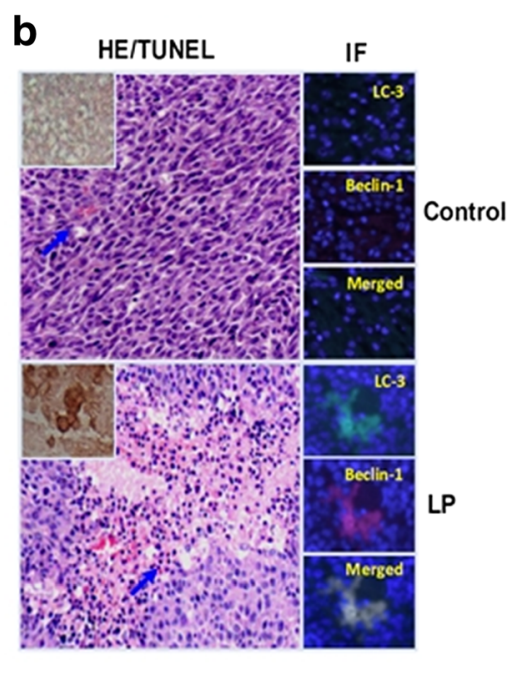

of trans-resveratrol in tumor tissues compared with that in brain tissues surrounding tumors $(P<0.05)$. (b) Parallel H\&E morphological staining, TUNEL apoptosis assays (upper left insets) and immunofluorescence colabeling (IF) of LC-3 (green) and Beclin-1 (red) were performed on rat intracranial glioblastomas without (control) and with LP administered trans-resveratrol. Arrows indicate the regions with higher magnification

treated with 1,3-bis- (2-chloroethyl) nitrosourea via intracarotid delivery and obtained survival prolongation with concentrations significantly lower than intravenous dosages [35]. LP delivery is minimally invasive and can be performed at the bedside under local anesthetic. The drug molecules are able to directly enter into the cerebrospinal fluid (CSF) and circulate within the central nervous system [36, 37]. So far, no report has described administration of resveratrol via these two approaches. According to our results, resveratrol injected at a dose of $4.56 \mu \mathrm{g} /$ $100 \mathrm{~g}$ body weight via the right ECA appeared in different brain regions within $2 \mathrm{~min}$ and the peak resveratrol concentration in the whole brain was observed after $10 \mathrm{~min}$ at $1.759 \pm 0.577 \mathrm{nmol} / \mathrm{g}(15.000 \pm 4.920 \mu \mathrm{M})$. When the same dose of resveratrol was injected via LP, a five-fold higher peak drug concentration $(7.700 \pm 0.734 \mathrm{nmol} / \mathrm{g} ; 65.662 \pm$ $6.259 \mu \mathrm{M})$ was observed in the whole brain. According to previous reports, resveratrol at this concentration elicits protective effects to glial cells exposed to lipopolysaccharide [38], to neurons under oxidative stress [26, 39] and to neurons after traumatic brain injury [28]. Trans-resveratrol molecules can be biotransformed to less active metabolites when they arrive in target organs [40]. That situation did not happen in this study because only the parental form of resveratrol (trans-resveratrol) was detected in brain tissues, which may be largely due to the instant entrance of the drug via "short-circuit routes" and the unchanged expression levels of brain-associated UGTs. Based on this evidence, it is reasonable to consider that ECA and, especially, LP administration can significantly improve brain resveratrol bioavailability to be 8.5 to 38.5 times higher with a 
dosage $6 \%$ lower than that administered by intraperitoneal injection. Additionally, in comparison with ECA injection, LP would be preferable for brain delivery because it is easier to perform, is less invasive and, most importantly, delivers a higher intracranial drug bioavailability [41, 42].

Although LP delivery can greatly increase resveratrol concentrations in brain tissues to $65.662 \pm 6.259 \mu \mathrm{M}$, it is not clear whether this concentration is sufficient to inhibit growth and to induce cell death of primary brain tumors. According to our previous findings, rat glioblastoma RG2 cells are subjected to growth arrest and apoptosis by constant $100 \mu \mathrm{M}$ resveratrol treatment for 72 hours or by daily 60 minute exposure to $150 \mu \mathrm{M}$ or $200 \mu \mathrm{M}$ resveratrol for 72 hours [17]. To mimic the brain dwell times of LP-administered resveratrol, RG2 cells were treated with $50 \mu \mathrm{M}, 100 \mu \mathrm{M}, 150 \mu \mathrm{M}$ or $200 \mu \mathrm{M}$ resveratrol for 20 or $30 \mathrm{~min}$. It was found that daily exposure of RG2 cells to $150 \mu \mathrm{M}$ and $200 \mu \mathrm{M}$ resveratrol even for 20 min inhibited RG2 cell growth within 3 days, and the inhibition rates were not statistically different between these two concentrations. Moreover, the peak drug uptakes of $150 \mu \mathrm{M}$ and $200 \mu \mathrm{M}$ resveratrol-treated cells were about $46.8 \%$ of and nearly two times higher than that of resveratrol administered by LP $(7.700 \pm 0.734 \mathrm{nmol} / \mathrm{g} ; 65.662 \pm$ $6.259 \mu \mathrm{M})$ but were maintained only for $10 \mathrm{~min}$ before decline. These phenomena suggest that the anti-cancer effects of resveratrol might depend on sufficient drug interaction with its multiple targeting sites and that the saturation of molecular targets may be largely determined by drug concentration rather than the duration of drug exposure. The suppressed growth and the enhanced autophagic activities in RG2 populations exposed daily to $150 \mu \mathrm{M}$ or $200 \mu \mathrm{M}$ resveratrol for $20 \mathrm{~min}$ for 3 days may support this notion. Since resveratrol at these concentrations has few unfavorable effects on normal rat glial cells and neurons [17], it is likely that an approximately two times higher drug uptake achieved by LP administration of resveratrol at $0.2 \mathrm{nmol} / \mathrm{g}$ body weight may exert similar effects on intracranial tumors without affecting normal brain functions. This has been further supported by the suppressive effects of LP-administered resveratrol on intracranial glioblastomas formed from RG2 cells in terms of upregulated expression of autophagy-related genes and extensive apoptosis in the tumor tissues. Our group is currently performing a more comprehensive study with this animal glioblastoma model to quantitatively evaluate the ability of this therapeutic approach in inhibiting tumor growth, in enhancing tumor radiosensitivity and in improving the life span and life quality of the tumor-bearing rats.

Taken together, this study provides direct evidence for the ability of resveratrol to cross the BBB and demonstrates for the first time the variable diffusion efficiencies of trans-resveratrol administered through intragastric, intraperitoneal, ECA and LP routes. The bioavailability of trans-resveratrol is well maintained in the brain samples analyzed. The peak concentrations of LP $50 \mu 1500 \mu \mathrm{M}$ resveratrol in the intracranial glioblastoma tissues are about three times higher than that in cultured RG2 glioblastoma cells treated with $150 \mu \mathrm{M}$ resveratrol for 20 or $60 \mathrm{~min}$. Given the evidence that resveratrol enhances autophagic and apoptotic activities in the in vitro and in vivo glioblastoma models, LP administration of resveratrol should be considered as an intervention approach in adjuvant managements of brain malignancies.

Acknowledgments This work was supported by grants from the National Natural Science Foundation of China (Nos. 81450016, 81272786, 81071971, 81072063 and 30971038), the Research Fund for PhD supervisors from the National Education Department of China (20122105110005), the Program Fund for Liaoning Excellent Talents in University (LJQ2012078) and the Program for Changiiang Scholar and Innovative Research Team in University (PCSIRT). The funders had no role in the study design, data collection and analysis, decision to publish, or preparation of the manuscript.

Required Author Forms Disclosure forms provided by the authors are available with the online version of this article.

Disclosure The authors declare that they have no conflicts of interest related to this manuscript.

\section{References}

1. Jang M, Cai L, Udeani GO, Slowing KV, Thomas CF, Beecher CW, et al. Cancer chemopreventive activity of resveratrol, a natural product derived from grapes. Science 1997; 275:218-20.

2. Mancuso R, del Valle J, Modol L, Martinez A, Granado-Serrano AB, Ramirez-Núñez $\mathrm{O}$, et al. Resveratrol improves motoneuron function and extends survival in SOD1 (G93A) ALS mice. Neurotherapeutics 2014;11:419-32.

3. Baur JA, Pearson KJ, Price NL, Jamieson HA, Lerin C, Kalra A, et al. Resveratrol improves health and survival of mice on a high-calorie diet. Nature 2006;444:337-42.

4. Juan ME, Vinardell MP, Planas JM. The daily oral administration of high doses of trans-resveratrol to rats for 28 days is not harmful. J Nutr 2002; 132: 257-60.

5. Sangeetha MK, Vallabi DE, Sali VK, Thanka J, Vasanthi HR. Subacute toxicity profile of a modified resveratrol supplement. Food Chem Toxicol 2013;59:492-500.

6. Wang Q, Xu J, Rottinghaus GE, Simonyi A, Lubahn D, Sun GY, et al. Resveratrol protects against global cerebral ischemic injury in gerbils. Brain Res 2002; 958: 439-47.

7. Patel KR, Scott E, Brown VA, Gescher AJ, Steward WP, Brown K. Clinical trials of resveratrol. Ann N Y Acad Sci 2011; 1215: 161-9.

8. Walle T. Bioavailability of resveratrol. Ann N Y Acad Sci 2011; 1215: 9-15.

9. Juan ME, Maijó M, Planas JM. Quantification of trans-resveratrol and its metabolites in rat plasma and tissues by HPLC. J Pharm Biomed Anal 2010; 51: 391-8.

10. Das S, Lin HS, Ho PC, Ng KY. The impact of aqueous solubility and dose on the pharmacokinetic profiles of resveratrol. Pharm Res 2008; 25:2593-600.

11. Brown VA, Patel KR, Viskaduraki M, Crowell JA, Perloff M, Booth $\mathrm{TD}$, et al. Repeat dose study of the cancer chemopreventive agent resveratrol in healthy volunteers: safety, pharmacokinetics, and effect on the insulin-like growth factor axis. Cancer Res 2010; 70: 9003-11. 
12. Burkhardt JK, Riina HA, Shin BJ, Moliterno JA, Hofstetter CP, Boockvar JA. Intra-arterial chemotherapy for malignant gliomas: a critical analysis. Interv Neuroradiol 2011; 17: 286-95.

13. Figueiredo EG, Faria JW, Teixeira MJ. Treatment of recurrent glioblastoma with intra-arterial BCNU [1, 3-bis (2-chloroethyl)-1nitrosourea]. Arq Neuropsiquiatr 2010; 68: 778-82.

14. Guerin C, Olivi A, Weingart JD, Lawson HC, Brem H. Recent advances in brain tumor therapy: local intracerebral drug delivery by polymers. Invest New Drugs 2004; 22: 27-37.

15. Seigers R, Schagen SB, Van Tellingen O, Dietrich J. Chemotherapyrelated cognitive dysfunction: current animal studies and future directions. Brain Imaging Behav 2013; 7: 453-9.

16. Liu HL, Hua MY, Chen PY, Chu PC, Pan CH, Yang HW, et al. Bloodbrain barrier disruption with focused ultrasound enhances delivery of chemotherapeutic drugs for glioblastoma treatment. Radiology 2010; 255: 415-25.

17. Shu XH, Li H, Sun XX, Wang Q, Sun Z, Wu ML, et al. Metabolic patterns and biotransformation activities of resveratrol in human glioblastoma cells: relevance with therapeutic efficacies. PLoS ONE 2011; 6: e27484.

18. Sun Z, Shi S, Li H, Shu XH, Chen XY, Kong QY, et al. Evaluation of resveratrol sensitivities and metabolic patterns in human and rat glioblastoma cells. Cancer Chemother Pharmacol 2013; 72: 965-73.

19. Valable S, Lemasson B, Farion R, Beaumont M, Segebarth C, Remy $\mathrm{C}$, et al. Assessment of blood volume, vessel size, and the expression of angiogenic factors in two rat glioma models: a longitudinal in vivo and ex vivo study. NMR Biomed 2008;21:1043-56.

20. Gu YT, Xue YX, Wang YF, Wang JH, Chen X, Shangguan QR, et al. Minoxidil sulfate induced the increase in blood-brain tumor barrier permeability through ROS/RhoA/PI3K/PKB signaling pathway. Neuropharmacology 2013;75:407-15.

21. Loch-Neckel G, Nemen D, Puhl AC, Fernandes D, Stimamiglio MA, Alvarez Silva M, et al. Stealth and non-stealth nanocapsules, containing camptothecin: in-vitro and in-vivo activity on B16-F10 melanoma. J Pharm Pharmacol 2007;59:1359-64.

22. Bock KW, Köhle C. UDP-glucuronosyltransferase 1A6: structural, functional, and regulatory aspects. Methods Enzymol 2005; 400: 57 75 .

23. Heydel JM, Holsztynska EJ, Legendre A, Thiebaud N, Artur Y, Le Bon AM. UDP-glucuronosyltransferases (UGTs) in neuro-olfactory tissues: expression, regulation, and function. Drug Metab Rev 2010; 42: 74-97.

24. Emlia Juan M, Buenafuente J, Casals I, Planas JM. Plasmatic levels of trans-resveratrol in rats. Food Res International 2002;35:195-9.

25. Green DR, Levine B. To be or not to be? How selective autophagy and cell death govern cell fate. Cell 2014;157:65-75.

26. Ates O, Cayli SR, Yucel N, Altinoz E, Kocak A, Durak MA, et al. Central nervous system protection by resveratrol in streptozotocininduced diabetic rats. J Clin Neurosci 2007;14:256-60.
27. Hall ED, Vaishnav RA, Mustafa AG. Antioxidant therapies for traumatic brain injury. Neurotherapeutics 2010;7:51-61.

28. Ates O, Cayli S, Altinoz E, Gurses I, Yucel N, Sener M, et al. Neuroprotection by resveratrol against traumatic brain injury in rats. Mol Cell Biochem 2007;294:137-44.

29. Ganapathy S, Chen Q, Singh KP, Shankar S, Srivastava RK. Resveratrol enhances antitumor activity of TRAIL in prostate cancer xenografts through activation of FOXO transcription factor. PLoS ONE 2010;5:e15627.

30. Roy P, Kalra N, Prasad S, George J, Shukla Y. Chemopreventive potential of resveratrol in mouse skin tumors through regulation of mitochondrial and PI3K/AKT signaling pathways. Pharm Res 2009;26:211-7.

31. Athar M, Back JH, Tang X, Kim KH, Kopelovich L, Bickers DR, et al. Resveratrol: a review of preclinical studies for human cancer prevention. Toxicol Appl Pharmacol 2007;224:274-83.

32. Sun Z, Li H, Shu XH, Shi H, Chen XY, Kong QY, et al. Distinct sulfonation activities in resveratrol-sensitive and resveratrolinsensitive human glioblastoma cells. FEBS J 2012;279:2381-92.

33. Tahara K, Miyazaki Y, Kawashima Y, Kreuter J, Yamamoto H. Brain targeting with surface-modified poly (D,L-lactic-co-glycolic acid) nanoparticles delivered via carotid artery administration. Eur J Pharm Biopharm 2011;77:84-8.

34. De la Calle JL, Paíno CL. A procedure for direct lumbar puncture in rats. Brain Res Bull 2002;59:245-50.

35. Bullard DE, Bigner SH, Bigner DD. Comparison of intravenous versus intracarotid therapy with 1,3-bis(2-chloroethyl)-1-nitrosourea in a rat brain tumor model. Cancer Res 1985;45:5240-45.

36. Wright BL, Lai JT, Sinclair AJ. Cerebrospinal fluid and lumbar puncture: a practical review. J Neurol 2012;259:1530-45.

37. Lavi R, Rowe JM, Avivi I. Lumbar puncture: it is time to change the needle. Eur Neurol 2010;64:108-13.

38. Zhang F, Shi JS, Zhou H, Wilson B, Hong JS, Gao HM. Resveratrol protects dopamine neurons against lipopolysaccharide-induced neurotoxicity through its anti-inflammatory actions. Mol Pharmacol 2010;78:466-77.

39. Fukui M, Choi HJ, Zhu BT. Mechanism for the protective effect of resveratrol against oxidative stress-induced neuronal death. Free Radic Biol Med 2010;49:800-13.

40. Gao S, Hu M. Bioavailability challenges associated with development of anti-cancer phenolics. Mini Rev Med Chem 2010;10:550 67.

41. Ceaglio N, Orozco G, Etcheverrigaray M, Mattio M, Kratje R, Perotti $\mathrm{N}$, et al. High performance collection of cerebrospinal fluid in rats: evaluation of erythropoietin penetration after osmotic opening of the blood-brain barrier. J Neurosci Methods 2013;219:70-5.

42. Mothe AJ, Bozkurt G, Catapano J, Zabojova J, Wang X, Keating A, et al. Intrathecal transplantation of stem cells by lumbar puncture for thoracic spinal cord injury in the rat. Spinal Cord 2011;49:967-73. 